\title{
Basic research on the formation characteristics of nitrated polycyclic aromatic hydrocarbons in the combustion process
}

\author{
K. Yasuda, N. Ishikawa, M. Watanabe, Y. Noma \& K. Kawamoto \\ Research Center for Material Cycles and Waste Management, \\ National Institute for Environmental Studies, Tsukuba, Japan
}

\begin{abstract}
Nitrated polycyclic aromatic hydrocarbons (nitro-PAHs) are widespread environmental pollutants that are generated by incomplete combustion. Many nitro-PAHs compounds are potential genotoxins and some are direct acting mutagens. Laboratory experiments using PAHs(pyrene, antracene and napthalene) in gas with coexisting nitrogen oxide and oxygen were conducted to elucidate the formation and decomposition behaviors of nitro-PAHs in the heating-reaction tube. It was found that the nitro-PAHs formed in a wide range of temperature from around $200-1000^{\circ} \mathrm{C}$, and that the concentrations of most the nitro-PAHs decreased with increasing heating temperature $\left(700-1000^{\circ} \mathrm{C}\right)$.

Keywords: heating-reaction tube, polycyclic aromatic hydrocarbon, nitration, formation characteristic, temperature dependence.
\end{abstract}

\section{Introduction}

Nitrated polycyclic aromatic hydrocarbons (nitro-PAHs) have been a focus of considerable concerns as potential mutagens and carcinogens [1]. Once released into the atmosphere, nitro-PAHs are highly persistent in the environment and can be transported long distances from their original sources [2,3]. Nitro-PAHs in the environment originate mainly from direct emissions from combustion sources, especially from diesel exhaust ${ }^{1}$. Nitro-PAHs emissions from municipal solid waste (MSW) incinerators have been studied using bioassays [4-7]. The results of quantitative analysis of nitro-PAHs in emissions of MSW incinerators have also been reported [8,9]. In these studies, however, a limited number of 
nitro-PAHs were studied only in final exit gases and ashes, and there is no information on the formation and decomposition behaviors of various nitroPAHs in waste combustion. We conducted laboratory experiments using PAHs(pyrene, antracene and napthalene) in gas with coexisting nitrogen oxide and oxygen to elucidate the formation and decomposition behaviors of nitroPAHs in a heating-reaction tube (hereinafter referred to as "reaction tube").

\section{Experimental procedures}

\subsection{Experimental apparatus and conditions}

Laboratory experiments were conducted in a horizontal cell type electric muffle furnace equipped with a quartz tube, $27 \mathrm{~mm}$ in diameter, and $800 \mathrm{~mm}$ in length. The furnace was connected to a permeater set to high temperature, as shown in Figure 1.

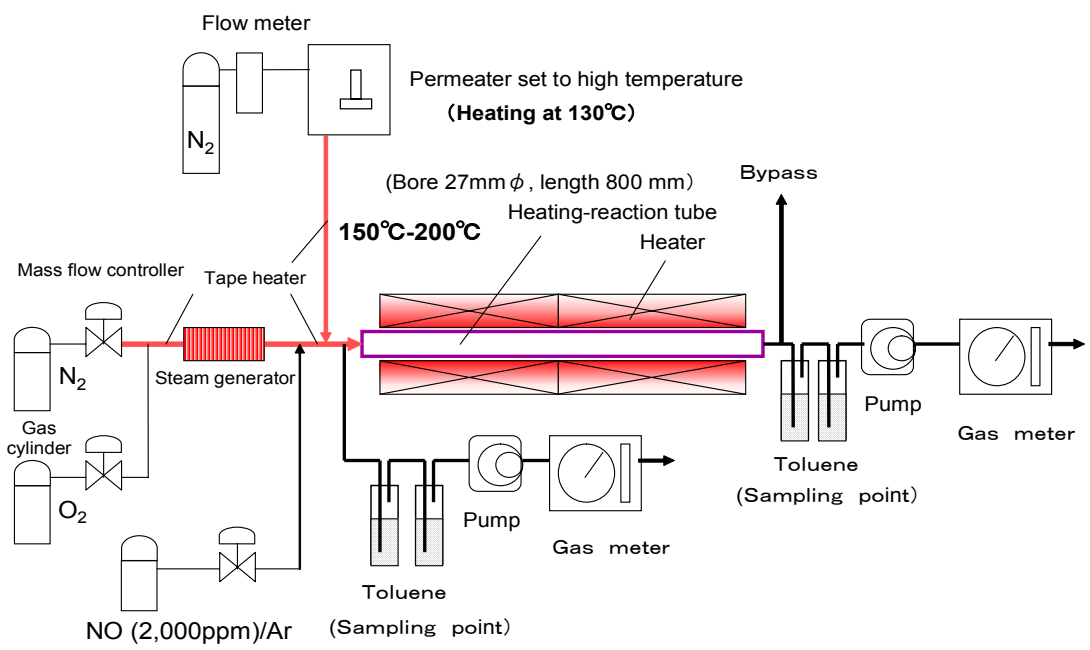

Figure 1: Schematic of experimental apparatus showing heating reaction flow.

Laboratory experiments were conducted using representative PAHs (pyrene, antracene and naphthalene) in gas with coexisting nitrogen oxide (nitric oxide: $\mathrm{NO}$ ) and oxygen $\left(\mathrm{O}_{2}\right)$. The heating temperature of the furnace was raised in the range of $200-1000^{\circ} \mathrm{C}$. Similarly to waste incinerators, the concentrations of $\mathrm{O}_{2}$ and $\mathrm{NO}$ were $10 \%$ and $150 \mathrm{ppm}$, respectively. Little reaction activity of nitrous oxide $\left(\mathrm{N}_{2} \mathrm{O}\right)$ was seen, but $\mathrm{NOx}$ were generated at heating temperature of $900^{\circ} \mathrm{C}$ and $1000^{\circ} \mathrm{C}$, as shown in Figure 2. Experiments using $\mathrm{N}_{2} \mathrm{O}$ were therefore conducted under two conditions at $900^{\circ} \mathrm{C}$ and $1000^{\circ} \mathrm{C}$. 


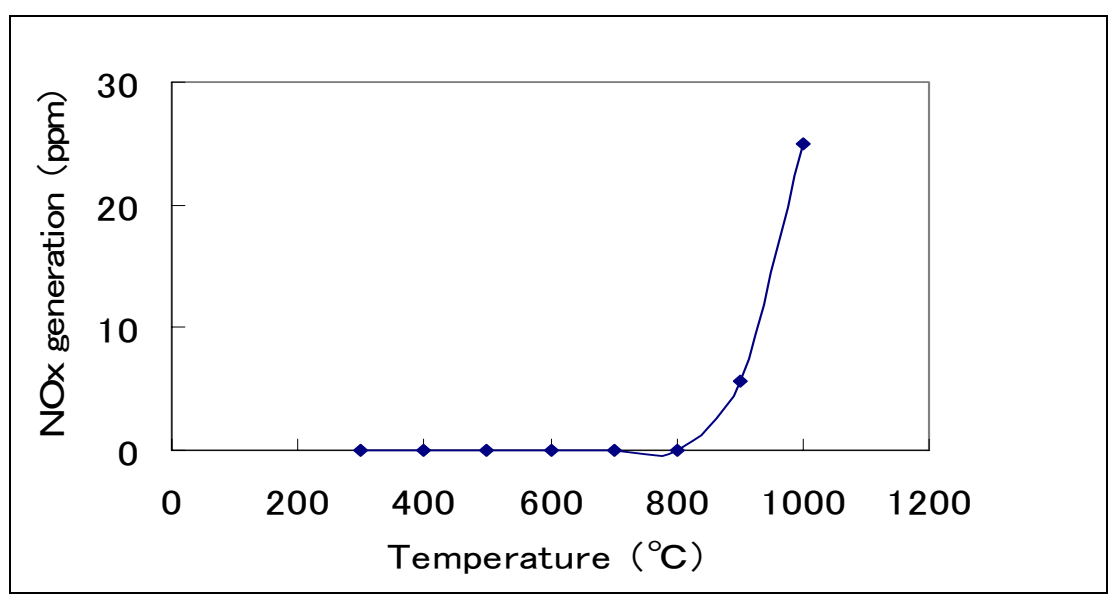

Figure 2: Correlation of $\mathrm{N}_{2} \mathrm{O}$ supply and $\mathrm{NOx}$ generation at outlet of reaction tube.

\subsection{Sampling and analysis}

Using the sampling system shown in Figure 1, gas was basically collected with toluene at the inlet and outlet of the heating-reaction tube. The typical sampling volume was $120-360 \mathrm{~L}$. During sampling the temperature of the sampling duct was maintained at $150-200^{\circ} \mathrm{C}$ by a tape heater. Identification and quantification of PAHs and nitro-PAHs were performed using gas chromatography-mass spectrometry with selected ion monitoring (GC/MS-SIM). An example of a chromatogram obtained by GC/MS-SIM is shown in Figure 3.

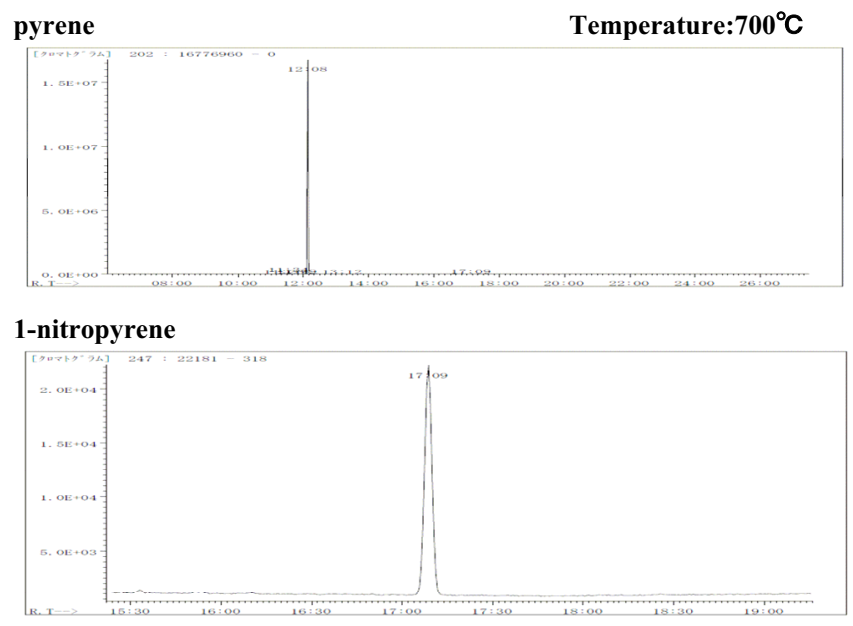

Figure 3: Example of chromatogram obtained by GC/MS-SIM at outlet of reaction tube. 


\section{Results and discussion}

\subsection{Pyrene}

The concentration of pyrene was about $60 \mu \mathrm{g} / \mathrm{m}^{3}$ at the inlet of the reaction tube. Sampling and analysis were carried out twice and the mean value was obtained.

\subsubsection{Temperature dependence of pyrene concentration at outlet of reaction tube}

Figure 4 shows the concentration of pyrene at various reaction-tube temperature. As can be seen in the figure, the decomposition of pyrene was promoted in proportion to the heating temperature at temperatures exceeding $600^{\circ} \mathrm{C}$, and the reduction was almost $100 \%$ at 900 and $1000^{\circ} \mathrm{C}$. In the case of $\mathrm{N}_{2} \mathrm{O}$, the result was the same for NO.

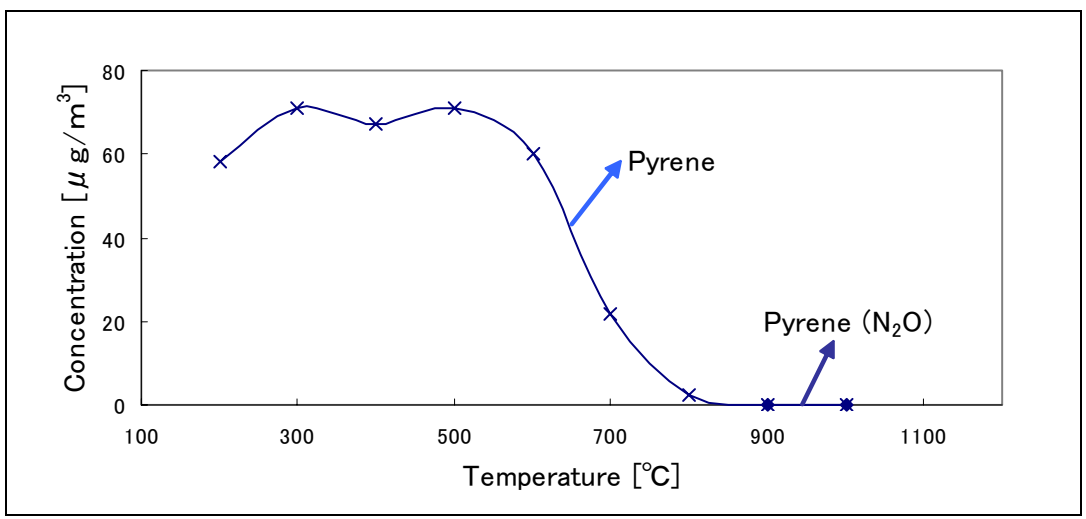

Figure 4: Temperature dependence of pyrene at the outlet of reaction tube.

\subsubsection{Temperature dependence of nitropyrene concentration at outlet of reaction tube}

Figure 5 shows the temperature dependence of 1-nitoropyrene concentrations at the outlet of the reaction tube. In the heating experiment using pyrene, the base product of nitro-PAHs was 1-nitropyrene. As shown in the figure, the concentration of 1-nitropyrene was the highest $\left(6.2 \mu \mathrm{g} / \mathrm{m}^{3}\right)$ at a temperature of $300^{\circ} \mathrm{C}$, then decreased with increasing temperature. Similarly to pyrene, the reduction was almost $100 \%$ at 900 and $1000^{\circ} \mathrm{C}$.

\subsubsection{Temperature dependence of dinitropyrene concentration at outlet of reaction tube}

Figure 6 shows the concentration of dinitropyrene at various reaction-tube temperature. The products of dinitropyrene were 1,3- and 1,8-dinitropyrene. The concentrations of both products were highest at a temperature of $500^{\circ} \mathrm{C}$, then decreased with increasing heating temperature. In the case of $\mathrm{N}_{2} \mathrm{O}$, however, the concentration of 1,8 -dinitoropyrene was slightly higher at $1000^{\circ} \mathrm{C}$ than that at $900^{\circ} \mathrm{C}$. 


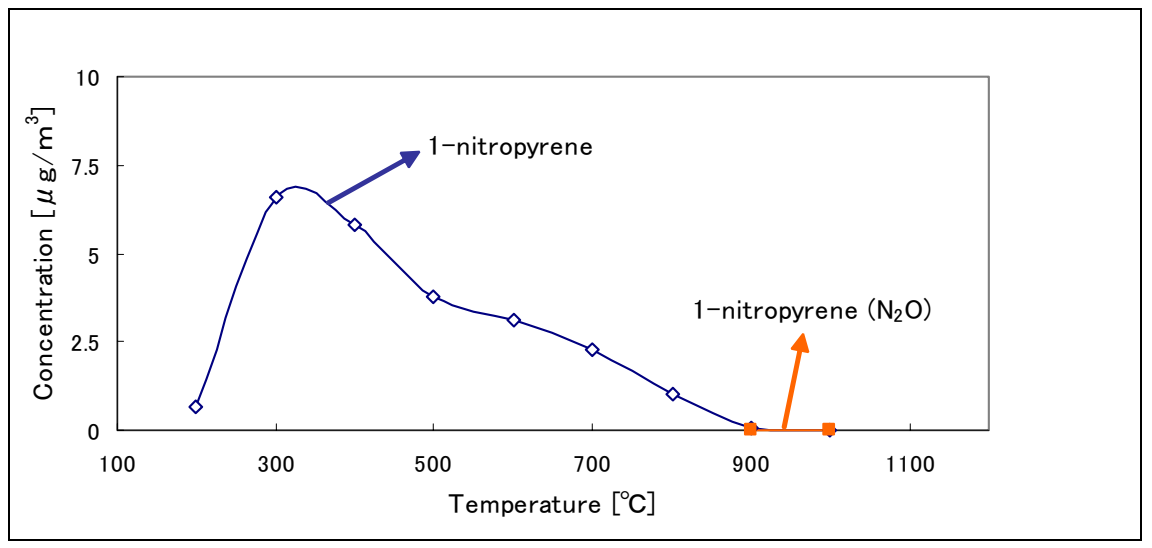

Figure 5: Temperature dependence of 1-nitoropyrene at outlet of reaction tube.

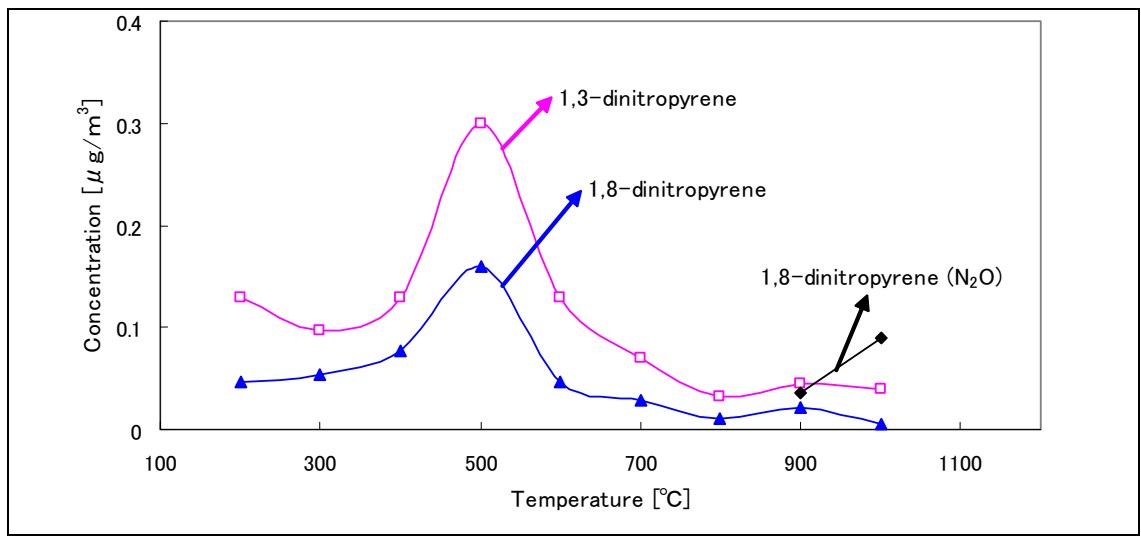

Figure 6: Temperature dependence of dinitro-PAHs at outlet of reaction tube.

\subsection{Anthracene}

The concentration of anthracene was about $100 \mu \mathrm{g} / \mathrm{m}^{3}$ at the inlet of the reaction tube. Sampling and analysis were carried out twice and the mean value was obtained.

\subsubsection{Temperature dependence of anthracene concentration at outlet of reaction tube}

Figure 7 shows the concentration of anthracene at various reaction-tube temperature. It can be seen that the tendency of anthracene decomposition was similar to that of pyrene. The reduction was almost $100 \%$ at 900 and $1000^{\circ} \mathrm{C}$. 


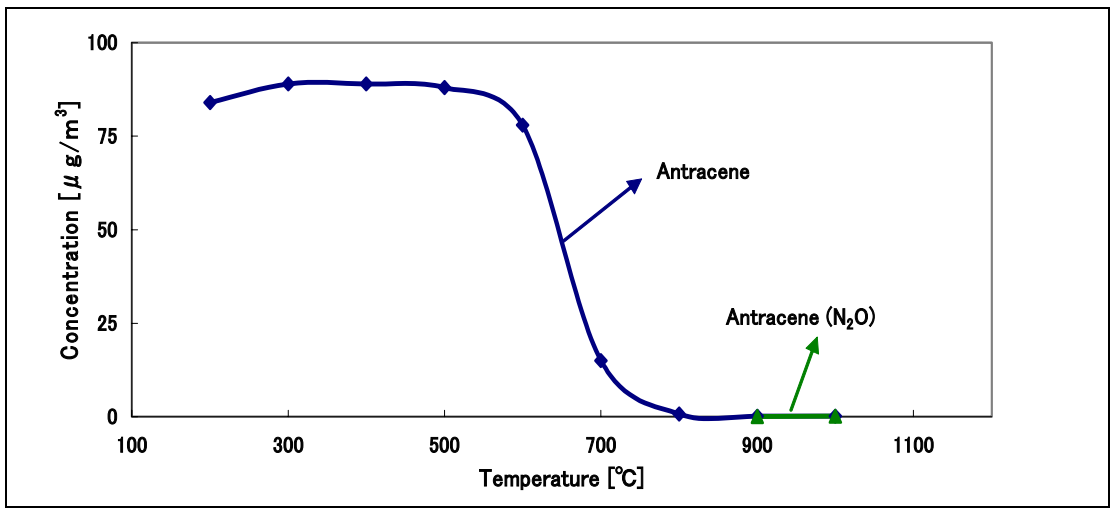

Figure 7: Temperature dependence of antrancene at outlet of reaction tube.

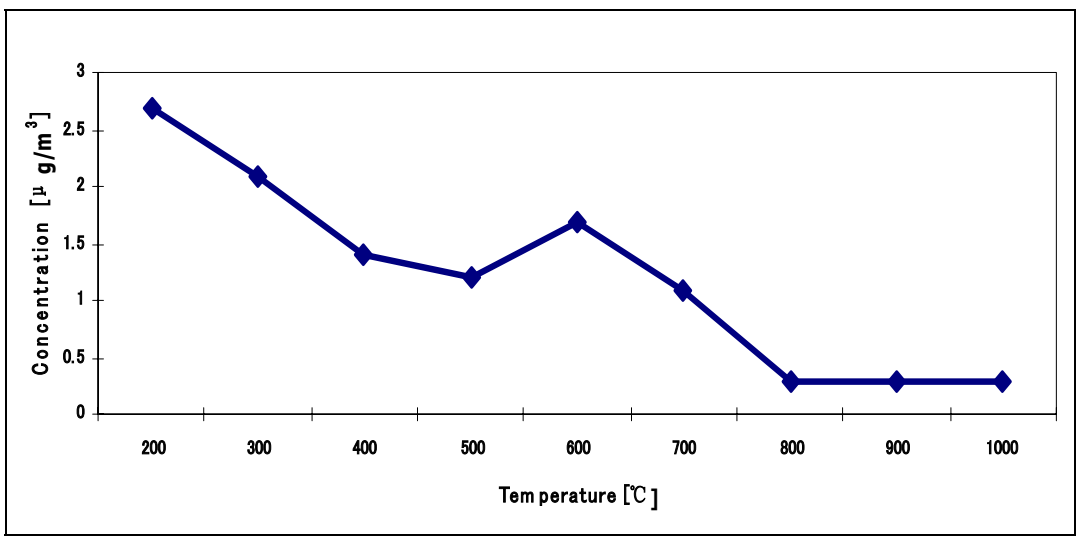

Figure 8: Temperature dependence of 9-nitroanthracene concentration at outlet of reaction tube.

\subsubsection{Temperature dependence of nitroanthracene concentration at outlet of reaction tube}

Figure 8 shows the temperature dependence of 9-nitoroanthracene concentration at the outlet of the reaction tube. In the heating experiment using anthracene, the only nitro-PAHs product was 9-nitroanthracene.

As show in the figure, the concentration of 9-nitroanthracene gradually decreased with increasing heating temperature.

\subsection{Naphthalene}

Using the sampling system of naphthalene shown in Figure 9, gas was basically collected with a Supelpak 20E tube matrix (polyurethane) (Supelco, Tokyo) at 
the inlet and outlet of the reaction tube. The typical sampling volume was $120 \mathrm{~L}$. During sampling the temperature of the sampling duct was maintained at $50^{\circ} \mathrm{C}$ by a tape heater. Acetone was used for the extraction of naphthalene and nitronaphthalene.

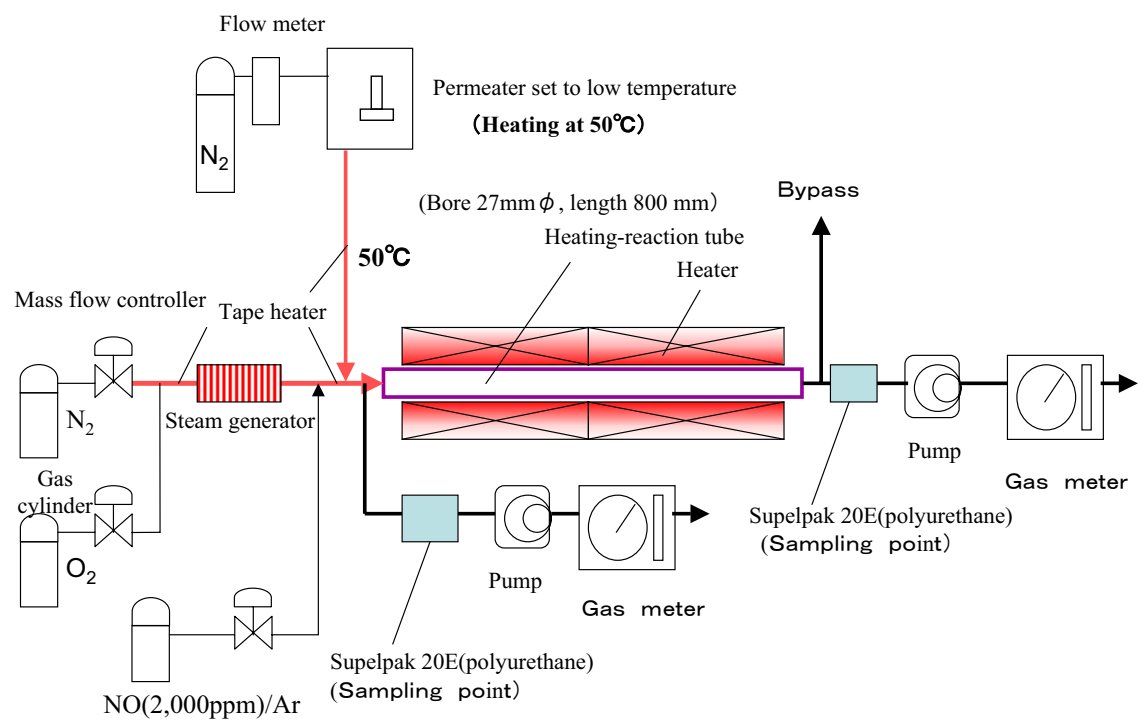

Figure 9: Schematic of experimental apparatus showing heating-reaction flow using naphthalene.

The concentration of naphthalene was about $100 \mu \mathrm{g} / \mathrm{m}^{3}$ at the inlet of the reaction tube. Sampling and analysis were carried out twice and the mean value was obtained.

\subsubsection{Temperature dependence of naphthalene concentration at outlet of reaction tube}

Figure 10 shows the concentration of naphthalene at various reaction-tube temperature. It can be seen that the tendency of naphthalene decomposition was similar to that of anthracene. The reduction was almost $100 \%$ at 900 and $1000^{\circ} \mathrm{C}$.

\subsubsection{Temperature dependence of nitronaphthalene concentration at the outlet of heating-tube}

In the heating experiment using naphthalene, there is no peak of nitro-PAHs at the chromatogram obtained by GC/MS-SIM.

\section{Conclusions}

- The decomposition of representative PAHs (pyrene, anthracene and naphthalene) was promoted in proportion to the heating temperature at temperature exceeding $600^{\circ} \mathrm{C}$, and the reduction was almost $100 \%$ at 800 $1000^{\circ} \mathrm{C}$. 


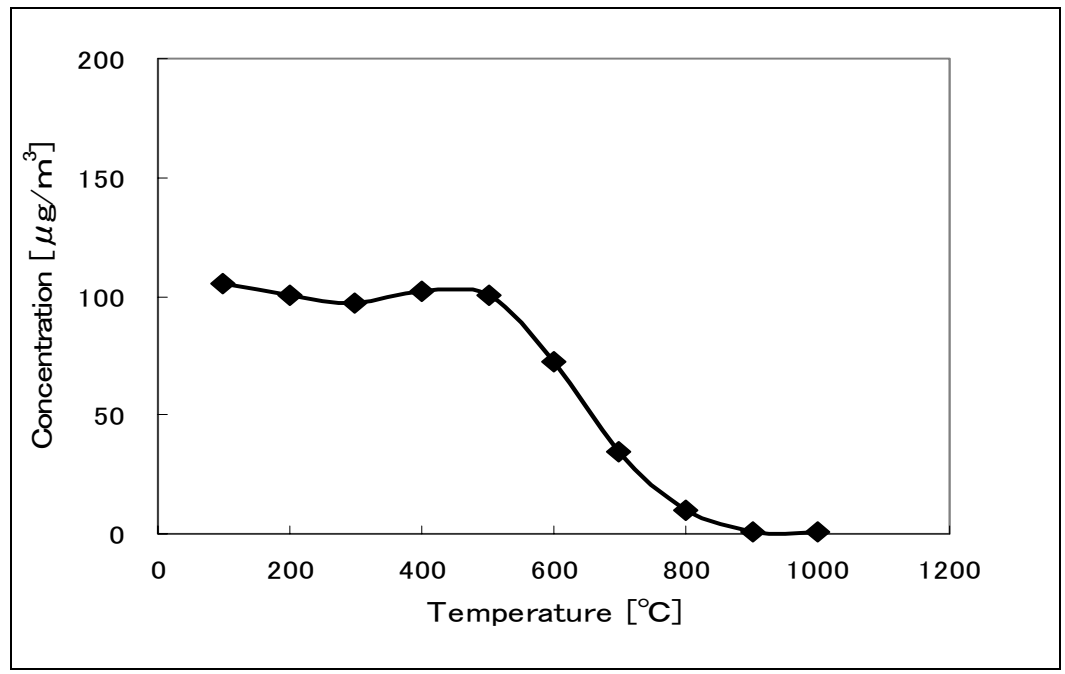

Figure 10: Temperature dependence of naphthalene at outlet of reaction tube.

- In the heating experiment using pyrene, the base product of nitro-PAHs was 1-nitropyrene. The concentration of 1-nitropyrene was highest $\left(6.2 \mu \mathrm{g} / \mathrm{m}^{3}\right)$ at a temperature $300^{\circ} \mathrm{C}$, then decreased with increasing temperature. The reduction was almost $100 \%$ at temperature of $900^{\circ} \mathrm{C}$ or higher, similarly to pyrene.

- The products of dinitropyrene were 1,3- and 1,8-dinitropyrene. In the case of these dinitropyrene products, the concentrations were highest at a temperature of $500^{\circ} \mathrm{C}$, then decreased with increasing temperature.

- In the heating experiment using anthracene, the only nitro-PAHs product was 9-nitroanthracene. The concentration of 9-nitroanthracene decreased with increasing temperature $\left(200-1000^{\circ} \mathrm{C}\right)$.

- In the heating experiment using naphthalene, the only nitro-PAHs product was 9-nitroanthracene. The concentration of 1-nitoronaphthalene decreased with increasing temperature $\left(100-1000^{\circ} \mathrm{C}\right)$.

- In the heating experiment using naphthalene, there is no peak of nitro-PAHs at the chromatogram obtained by GC/MS-SIM.

\section{References}

[1] World Health Organization: Environmental Health Criteria 229, 447, (2003).

[2] Nielsen T, Seitz B. and Ramdahl T.: Atmos. Environ. 18, 2159 (1984).

[3] Feilberg A, Poulsen M.W, Nielsen T. and Skov H.: Atmos. Environ. 35, 353 (2001).

[4] Kamiya A. and Ose Y.: Sci. Total Environ. 61, 37 (1987).

[5] Kamiya A. and Ose Y.: Sci. Total Environ. 65, 109 (1897).

[6] Yoshino H. and Urano K.: Total Environ. 162, 23 (1995). 
[7] DeMarini D.M, Shelton M.L. and Bell D.A.: Mutat. Res. 349, 1 (1996).

[8] Wiencke J, Kruse H, Huckfeldt U, Eickhoff W. and Wassermann O.: Chemosphere 30, 907 (1995).

[9] Yoshida H, Akiyama K, Kamataki H, Tatsuichi S, Kitamura K, Ueno H. and Iwasaki Y.: Tokyo-to Kankyo Kagaku Kenkyuusyo Nenpou (in Japanese) 155 (1998). 